\title{
Treino de mães na interação com os filhos durante a realização da tarefa escolar
}

\author{
Mother's interaction training during their \\ children's homework activity
}

\author{
Paula Brandão SCARPELLI \\ Carlos Eduardo COSTA2 \\ Sílvia Regina de SOUZA ${ }^{2}$
}

\begin{abstract}
Resumo
O estudo avaliou a efetividade de um procedimento de treino de mães sobre as categorias comportamentais "reforçar o comportamento da criança", "punir o comportamento da criança", "dar instruções para a criança"e "fazer o exercício pela criança". Participaram duas duplas de mães e filhos. Tarefas de matemática foram entregues à dupla para que a criança as realizasse sob a supervisão da mãe (Fase 1). Na Fase 2 a pesquisadora ficou dentro da sala, mas sem intervir. Na Fase 3, foi utilizado um procedimento de economia de fichas. Após o término dessa fase, as Fases 2 e 1 foram reimplementadas. Para a Dupla 1, houve um aumento na taxa média de respostas para a categoria "reforçar" e uma diminuição para as categorias "punir"e "fazer o exercício". Para a Dupla 2, houve um ligeiro aumento na taxa média de respostas para a categoria "reforçar" e uma diminuição na categoria "fazer o exercício". Foram propostas modificações no procedimento original para o aprimoramento da metodologia de intervenção.
\end{abstract}

Palavras-chave: crianças; desenvolvimento escolar; relação mãe-criança.

\begin{abstract}
The study has evaluated the effectiveness of a mother's training procedure on the behavior categories "to reinforce the child's behavior", "to punish the child's behavior", "to give instructions for the child" and "to do the exercise for the child". Two pairs of mothers and children had participated in this research. Mathematics tasks were delivered to the pairs, and children should complete them under mother's supervision (Phase 1). In Phase 2, the researcher was inside the room, without intervening. In Phase 3, the token's economy procedure was used. After ending Phase 3, Phases 2 and 1 were re-implemented. In Pair 1 there was an increase of answers on category "to reinforce", a decrease on categories "to punish", and "to do the exercise". On Pair 2 there was an increase of answers on category "to reinforce", and a decrease on category "to do the exercise". Modifications in original procedure had been proposed to improve the methodology intervention.
\end{abstract}

Key words: children; school performance; mother child relations.

$\boldsymbol{\nabla} \mathbf{v} \boldsymbol{\nabla}$

1 Acadêmica do Curso de Especialização em Psicoterapia na Análise do Comportamento. Universidade Estadual de Londrina. Londrina, PR, Brasil.

2 Professores Doutores, Departamento de Psicologia Geral e Análise do Comportamento. Universidade Estadual de Londrina. Rod. Celso Garcia Cid, PR 445, km 380, Caixa Postal 6001,86051-990, Londrina, PR, Brasil. Correspondência para/Correspondence to: S.R.SOUZA.E-mail:<ssouza@sercomtel.com.br>. 
Keith e Cooper (1986 apud Jenson, Sheridan, Olympia \& Andrews, 1994) definem tarefa escolar como um trabalho que os professores atribuem aos alunos para ser concluído fora do período normal de aula, com o objetivo de estender a prática de habilidades acadêmicas a outros ambientes.

A realização da tarefa escolar pode trazer muitas vantagens para os alunos, entre elas: o desenvolvimento de habilidades cognitivas específicas, como a solução de problemas; motivação para a aprendizagem; aperfeiçoamento das atitudes dos alunos em relação à escola e aperfeiçoamento de hábitos de estudo como tempo despendido na realização da tarefa e responsabilidade (Eiliam, 2001).

Dessa forma, considerando que a tarefa é realizada em casa, o ambiente familiar pode ser uma importante variável no desenvolvimento escolar das crianças. Sabe-se que recursos materiais presentes nesse ambiente e o envolvimento dos pais podem favorecer o desenvolvimento acadêmico de uma criança (Fehrmann, Keith \& Reimers, 1987; Grolnick \& Slowiaczek, 1994; Marturano, 1999; Eiliam, 2001).

De acordo com Jenson et al. (1994) os pais podem ajudar os filhos a fazerem a tarefa de muitas maneiras: primeiramente, deve-se ter recursos materiais em casa, como livros, dicionários e outros instrumentos acadêmicos. Além disso, comportamentos específicos dos pais (por exemplo, encorajar a realização da tarefa, discutir tópicos da tarefa etc.) podem contribuir para o desempenho acadêmico das crianças.

Pesquisadores como Fehrmann et al. (1987) também afirmam que o envolvimento dos pais com a escola é uma importante variável para promover o desempenho acadêmico. Esses autores descrevem alguns comportamentos dos pais que podem ter essa função, como expectativa em relação ao desempenho escolar do filho, encorajamento verbal ou interações que dizem respeito à escola, reforçamento direto para aperfeiçoar o desempenho escolar entre outros.

De acordo com Hübner e Marinoti (2000), os problemas de estudo são estabelecidos e mantidos por contingências de ensino. Os problemas no comportamento de estudar podem estar relacionados às condições antecedentes, às classes de respostas e às condições conseqüentes desse comportamento.
Dessa forma, os pais têm um papel importante ao estabelecer e manter o comportamento de estudar dos filhos.

Para Hübner (1999) a atuação dos pais em relação ao comportamento de estudar pode se dar nas condições antecedentes como, por exemplo, a disponibilidade de materiais e em relação às conseqüências desse comportamento. Quanto às conseqüências, elas podem ser aversivas ou reforçadoras.

Matos (1993) faz uma análise de contingências no aprender e no ensinar e afirma que é importante especificar o comportamento que se deseja ensinar e reforçá-lo imediatamente após a sua ocorrência. Essas considerações corroboram com as de Hübner (1999) e Hübner e Marinotti (2000) e sugerem que o comportamento de estudar pode ser aprendido pelas crianças e mantido por pais e professores.

No entanto, as condutas inadequadas dos pais podem acentuar os comportamentos inadequados das crianças relacionados ao estudo, principalmente de crianças com dificuldades de aprendizagem (Hübner, 1999).

O que pode acontecer muitas vezes é que, devido às reclamações da escola, em casa, os pais mudam o seu comportamento e passam a usar esquemas de reforçamento inconsistentes, acentuando-se o uso da punição. O aumento no uso da punição relacionada à tarefa escolar tende a diminuir a freqüência desses comportamentos (Matos, 1993), diminuindo assim a probabilidade de ocorrência de comportamentos adequados em relação ao estudo. Com isso há uma diminuição também na probabilidade de ocorrência de reforços contingentes a tais comportamentos (Hübner \& Marinoti, 2000).

Além disso, crianças com dificuldades de aprendizagem cometem mais erros, e situações que geram erros são punitivas (Matos, 1993). Dessa forma, o comportamento de estudar das crianças com dificuldades de aprendizagem pode ser freqüentemente punido tanto pelos pais quanto pelo seu próprio desempenho, o que pode gerar diminuição na freqüência de respostas de estudar e um aumento na esquiva de situações de estudo (que se tornaram aversivas) por parte da criança. 
Outras vezes, ainda, os pais acabam fazendo o exercício (a tarefa) pela criança ou dando a resposta correta. Ao fazer isso, os pais reforçam positivamente o comportamento inadequado da criança (de sempre pedir e esperar pela resposta, não resolvendo o exercício sozinha) e o comportamento dos pais é reforçado negativamente (por livrarem-se mais rapidamente da obrigação de ajudar os filhos na realização da tarefa escolar). Tudo isso pode acarretar um aumento na freqüência dos comportamentos inadequados dos pais e dos filhos com relação ao estudo (Zagury, 2002; Soares, Souza \& Marinho, 2004).

De acordo com Zagury (2002), existem alguns comportamentos dos pais que podem favorecer a aprendizagem e o desempenho escolar dos filhos. Segundo a autora, "criar bons hábitos" de estudo desde cedo evita que os filhos tenham problemas escolares no futuro. Assim, segundo Zagury, os pais devem: (a) reforçar o comportamento da criança de fazer tarefa; (b) arrumar um espaço adequado que será o local de estudo; (c) combinar com a criança o horário das tarefas; (d) supervisionar a tarefa; (e) esclarecer as dúvidas da criança e deixar que ela conclua o resto.

Além do que citou Zagury (2002), a utilização de reforços condicionados generalizados, como, por exemplo, o uso de fichas, pode contribuir para estabelecer repertórios iniciais e manter comportamentos aprendidos até que haja a transferência do controle exercido pelas fichas a reforçadores naturais. $\mathrm{O}$ uso de reforçadores condicionados generalizados pode ser realizado para manter comportamentos temporalmente distantes do reforçador principal (Tomanari, 2000), sendo um procedimento utilizado com dois objetivos: primeiro, "instalar e manter comportamentos desejáveis no decorrer das condições de tratamento" (Tomanari, p.66) e, segundo, "promover uma forma de facilitar a manutenção desses comportamentos, depois que o tratamento tenha sido descontinuado, transferindo o controle exercido pelas fichas a reforçadores naturais" (Tomanari, p.66), por exemplo, a melhora no desempenho escolar, o aumento na freqüência dos comportamentos de estudo da criança etc. Dessa forma, o comportamento primeiramente instalado e mantido por um reforçador arbitrário (fichas) no decorrer do processo pode passar a ser controlado por outras variáveis naturalmente reforçadoras.
Sampaio, Souza e Costa (2004) realizaram um estudo cujo objetivo foi ensinar as mães a liberarem conseqüências para os comportamentos de seus filhos que eram compatíveis com a realização da tarefa de casa. Participaram dessa pesquisa duas mães e duas crianças com oito anos de idade que cursavam a segunda série e que, de acordo com a professora, apresentavam "dificuldades de aprendizagem". Foram consideradas como apresentando "dificuldades de aprendizagem" crianças que não traziam suas tarefas feitas ou cometiam muitos erros ao realizá-las, que não conseguiam realizar os exercícios propostos em sala de aula e tinham dificuldade em acompanhar o ritmo da turma.

Considerando a ampla literatura nacional e internacional sobre a temática relativa às "dificuldades de aprendizagem", o termo neste estudo foi utilizado mais como uma estratégia para obtenção dos participantes. Foram realizadas sessões de linha de base nas quais tarefas eram dadas para que a criança as realizasse sob a supervisão da mãe. Em uma fase subseqüente, as mães foram submetidas a um treinamento que abordou, através de palestras (i.e. instruções), os seguintes tópicos: (a) a importância do elogio; (b) os efeitos adversos da punição; (c) a eliminação de estímulos concorrentes com a tarefa de casa; (d) a extinção de respostas incompatíveis com a realização da tarefa de casa e (e) o uso de instruções para o entendimento da tarefa. Após cada palestra uma nova tarefa era dada à criança que a deveria realizar sob supervisão da mãe. Todas as sessões foram filmadas e, depois, as taxas dos comportamentos de dar instruções, conferir a tarefa, elogiar o desempenho da criança, agredir, apontar erros na resposta dada pela criança, responder/fazer a atividade pela criança e chamar a atenção da criança foram computadas. Os resultados sugeriram que o treinamento dado às mães foi efetivo para aumentar a taxa da resposta da mãe de conferir a tarefa e elogiar; e diminuir a taxa de comportamentos da mãe de dar a resposta pela criança ou fazer a atividade por ela.

Apesar de terem sido observadas mudanças nas taxas dos comportamentos das mães através desse procedimento de treinamento, Sampaio et al. (2004) propuseram algumas mudanças no delineamento da pesquisa. Entre elas, cita-se a necessidade de um 
treinamento no qual os comportamentos da mãe pudessem ser modelados diretamente em vez de apenas instruídos verbalmente.

Sendo assim, o presente trabalho pretendeu avaliar a efetividade de um procedimento de treino de mães enquanto elas interagiam com os filhos durante a realização da tarefa de casa. $O$ procedimento de treino de mães teve como objetivo aumentar a freqüência dos comportamentos adequados da mãe (reforçar positivamente o comportamento da criança quando acerta um exercício e dar instruções para ela chegar à resposta correta) e diminuir a freqüência dos comportamentos inadequados (punir o comportamento da criança quando ela errar um exercício e fazer o exercício pela criança). Diferentemente do trabalho realizado por Sampaio, Souza e Costa (2004), no presente trabalho, a pesquisadora interveio diretamente sobre o comportamento das mães durante as sessões em que as crianças, acompanhadas por elas, realizaram os exercícios propostos.

\section{Método}

\section{Participantes}

Participaram da pesquisa duas duplas de mães e filhos indicadas pela diretora e selecionadas de acordo com a disponibilidade de horário das mães. As crianças, um menino e uma menina, estavam cursando a $2^{\text {a }}$ série do ensino fundamental e tinham oito e nove anos, respectivamente, no início do estudo e apresentavam, de acordo com a professora, dificuldade de aprendizagem caracterizada por notas baixas, não fazer as atividades em sala de aula e não fazer regularmente a tarefa. As mães eram donas de casa e tinham 37 anos. Uma possuía o ginásio incompleto e a outra o colegial incompleto.
O local foi uma sala de aproximadamente $10 \mathrm{~m}^{2}$ de uma escola municipal de pré-escola a quarta série do ensino fundamental, localizada na periferia da cidade de Londrina. Na sala havia uma mesa, duas cadeiras e, durante as sessões, uma filmadora fixada sobre um tripé há aproximadamente três metros das duplas. A coleta de dados foi realizada durante um período de doze semanas. Nesse período, foram realizadas em média duas sessões experimentais por semana com duração aproximada de meia hora cada.

Quanto aos equipamentos e materiais, foram utilizados filmadora, fitas de vídeo, papéis, lápis e fichas de cartolina (azul claro e escuro, bege claro e escuro).

\section{Procedimento}

A pesquisa foi realizada em cinco fases. Cada dupla passou pelas fases separadamente e sem contato uma com a outra. As sessões de interação entre mãe e criança durante a realização de exercícios de matemática, elaborados pela pesquisadora, foram filmadas ${ }^{3}$.

Fase 1 - Linha de Basel: nesta fase, estavam dentro da sala a mãe e a criança. Os comportamentos emitidos pela mãe foram filmados e, posteriormente, foi registrada a freqüência dos seguintes comportamentos: reforçar o comportamento da criança quando ela acertar um exercício ${ }^{4}$; dar instruções; punir quando ela errar um exercício e fazer o exercício pela criança (Tabela 1).

O registro dos comportamentos das mães, a partir das fitas, foi realizado por duas pessoas: a pesquisadora e a assistente de pesquisa. A assistente, que recebera treinamento para a realização dos registros, desconhecia os objetivos da pesquisa e não participava das sessões experimentais.

A concordância entre os registros feitos pela pesquisadora e pela assistente foi calculada e foram considerados os registros cuja concordância fosse maior que $80 \%$.

\footnotetext{
3 A pesquisadora investigou os conteúdos ensinados em matemática durante o ano. A tarefa de matemática foi escolhida porque as respostas dos exercícios não deixavam dúvidas para as mães sobre quando elas estavam corretas ou não. Durante as sessões, os exercícios foram se tornando gradualmente mais complexos a fim de evitar que, com o decorrer da pesquisa, as crianças tivessem menos dificuldade em fazer os exercícios e isso interferisse nos resultados.

4 Todavia, o termo "reforço" no presente trabalho não levou em consideração o efeito que o comportamento da mãe teve sobre o comportamento do filho. Por exemplo, se a mãe elogiou ou sorriu para a criança após a realização correta de um exercício e a criança estava olhando em direção à mãe, esse comportamento foi contado como uma instância do comportamento de"'reforçar o comportamento da criança quando ela acertar um exercício", embora não se tenha registrado se o comportamento da mãe realmente teve uma função reforçadora sobre o comportamento da criança. O mesmo vale para a categoria "punir o comportamento da criança quando ela errar um exercício".
} 
Tabela 1. Categorias comportamentais das mães que foram registradas e analisadas (extraída de Sampaio, Souza e Costa, 2004 e modificada para a realização desta pesquisa).

\begin{tabular}{|c|c|c|c|}
\hline & Categoria & Descrição & Exemplos \\
\hline \multirow{2}{*}{ 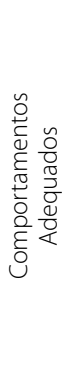 } & Dar Instruções & $\begin{array}{l}\text { Verbalizações sobre os passos que a criança deve } \\
\text { seguir para a realização do exercício proposto na } \\
\text { tarefa, porém, não disponibilizando a resposta } \\
\text { para criança. Inclui perguntas que levam a } \\
\text { criança a refletir sobre as atividades da tarefa. }\end{array}$ & $\begin{array}{l}\text { Pegue o caderno; passe o traço; pule uma linha; leia } \\
\text { novamente; apague o que escreveu; o que está escrito } \\
\text { aqui?; Como será que se faz este problema?; Como a } \\
\text { professora ensinou fazer esta continha? Coloque isto que } \\
\text { você disse aqui; verifique se está certo, } 3 \times 4 \text { ? b }+ \text { a? etc. }\end{array}$ \\
\hline & Reforço Positivo & $\begin{array}{l}\text { Reforçar positivamente o comportamento da } \\
\text { criança de realizar um exercício, ou parte dele } \\
\text { corretamente. Através da apresentação de elogio } \\
\text { verbal, reforço não verbal e/ou físico. }\end{array}$ & $\begin{array}{l}\text { Elogios verbais: Isso mesmo; certo; ótimo; você é muito } \\
\text { inteligente; jóia; muito bem; parabéns, etc. Reforço não } \\
\text { verbal: sorrir, piscar os olhos, acenar positivamente com a } \\
\text { cabeça. Reforço físico: administração de carinhos (passar } \\
\text { a mão na cabeça e em outras partes do corpo), beijar, } \\
\text { abraçar, etc. }\end{array}$ \\
\hline \multirow{2}{*}{ 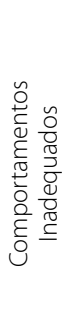 } & Punição & $\begin{array}{l}\text { Aplicação de agressões verbais ou não verbais. } \\
\text { Essa categoria engloba agressões que causam } \\
\text { constrangimento na criança agredida. O agressor } \\
\text { é irônico e repressivo diante das respostas dadas } \\
\text { pela criança. }\end{array}$ & $\begin{array}{l}\text { Agressões não verbais: tapas, beliscões, puxão pelo braço, } \\
\text { corrigir agressivamente, aceno negativo com a cabeça. } \\
\text { Agressões verbais: broncas, gritos, resmungar, lamentar } \\
\text { (Não é assim que se faz; faça direito; fique quieta!; sua } \\
\text { burra; incompetente; nunca vai conseguir aprender desse } \\
\text { jeito; parece que você está no mundo da lua, etc.). }\end{array}$ \\
\hline & $\begin{array}{l}\text { Responder/Fazer a } \\
\text { atividade pela criança }\end{array}$ & $\begin{array}{l}\text { Verbalizações diretas que indicam a resposta } \\
\text { correta ou mesmo a realização da atividade para } \\
\text { a criança. }\end{array}$ & $\begin{array}{l}\text { A mãe fornece a resposta do exercício - Dois mais dois } \\
\text { são quatro ou executa a tarefa pela criança - escreve no } \\
\text { livro, no caderno, faz cópia, resolve o problema, responde } \\
\text { à pergunta, apaga pela criança e etc. }\end{array}$ \\
\hline
\end{tabular}

Durante a Fase 1, foi realizada a análise visual dos gráficos construídos a partir dos registros das sessões experimentais e quando os comportamentos registrados se mostraram estáveis e sem tendência essa fase foi interrompida e foi dado início à Fase 2.

Fase 2 - Linha de Base ll: nesta fase, a pesquisadora permaneceu dentro da sala, mas sem intervir, com o objetivo de verificar se iriam ocorrer mudanças nas freqüências dos comportamentos emitidos pela mãe, devido à simples presença da pesquisadora. Foram realizadas três sessões com cada dupla nessa fase.

Antes de começar as sessões, a pesquisadora deu a seguinte instrução: "A partir desta fase, durante as sessões, eu estarei dentro da sala, mas não vou fazer nada e não poderei tirar dúvidas, só vou assistir".

Fase 3 - Intervenção: a intervenção foi programada sobre cada comportamento observado e registrado nas Fases 1 e 2 e teve por objetivos: aumentar a freqüência dos comportamentos das mães de (a) reforçar os comportamentos da criança quando ela acertasse um exercício e (b) dar instruções para a criança chegar a resposta correta; diminuir a freqüência dos comportamentos das mães de: (a) punir o comportamento da criança quando ela errasse um exercício e (b) fazer o exercício pela criança.
Para isso foi utilizado um procedimento no qual fichas de cores diferentes eram liberadas como conseqüência para os comportamentos de cada uma das mães e as fichas poderiam ser trocadas por prêmios ao final de cada etapa dessa fase.

A Fase 3 foi realizada em quatro etapas nas quais instruções eram dadas no início de cada sessão para cada uma das mães sem a presença das crianças.

- Etapa A: foram realizadas três sessões nessa etapa. Antes de começar a primeira sessão, a mãe respondeu a um questionário para levantamento dos prêmios que seriam trocados pelas fichas (e.g., presilhas, produtos de beleza, utensílios de cozinha). A pesquisadora também explicou para ela a importância do reforço positivo contingente ao comportamento adequado do filho. Para explicar essa relação, a pesquisadora utilizou trechos do livro "Pais Perfeitos" (Guhl \& Fontenelle, 1997), com exemplos de pais reforçando um comportamento adequado do filho e as possíveis conseqüências.

Em seguida, explicou que quando a mãe reforçasse o comportamento do filho quando ele acertasse um exercício, a pesquisadora iria mostrar a ela uma ficha azul escuro que seria guardada. Ao final dessa etapa, ela poderia trocar as fichas azuis por prêmios. Quanto maior o número de fichas azuis, melhor o prêmio. 
Feito isso, a criança foi chamada para entrar na sala e a primeira sessão foi iniciada. As sessões seguintes foram iniciadas sem uma instrução prévia da pesquisadora, que apenas perguntava à mãe se ela "lembrava" do que seria realizado e esclarecia as dúvidas. O mesmo procedimento foi realizado nas etapas seguintes.

Ao final de cada sessão, em todas as etapas da intervenção, as fichas eram contadas pela mãe e pela pesquisadora e registradas em um cartão.

- Etapa B: foram realizadas três sessões nessa etapa. A pesquisadora iniciou a sessão falando sobre a importância das instruções para que a criança chegue ao resultado correto de um exercício. Para explicar isto, ela elaborou vinhetas, que apresentou em vídeo, com trechos das sessões anteriores das mães em que elas davam a resposta do exercício para a criança e de quando davam instruções para que ela chegasse à resposta correta, discutindo em seguida cada uma das situações. Posteriormente, foi dito às mães que, assim como na Etapa A, para cada comportamento de reforçar o desempenho correto do filho seria apresentada uma ficha azul escuro e quando a mãe desse instruções para que o filho resolvesse o exercício sozinho seria apresentada uma ficha azul claro. Todas as fichas azuis seriam somadas para a obtenção do prêmio.

- Etapa C: foi realizada uma sessão nessa etapa. A pesquisadora discutiu com a mãe os efeitos da punição sobre os comportamentos da criança. Para isso a pesquisadora utilizou trechos do livro "Pais Perfeitos" (Guhl \& Fontenelle, 1997) para explicar as possíveis conseqüências da punição sobre o comportamento do filho. A pesquisadora explicou também que para cada comportamento de reforçar o desempenho correto do filho seria apresentada uma ficha azul escuro. Quando a mãe fornecesse instruções para que o filho chegasse à resposta correta seria apresentada uma ficha azul claro, e toda vez que ela punisse o comportamento da criança quando ela errasse um exercício, seria apresentada uma ficha bege escuro. Para cada ficha bege escuro apresentada seria retirada uma ficha azul no final da sessão.

- Etapa D: foram realizadas duas sessões nessa etapa. Discutiu-se sobre os problemas de se fazer o exercício pela criança. Para isso, a pesquisadora utilizou cartazes com situações hipotéticas e ilustrativas de um pai resolvendo um exercício pelo filho, como por exemplo um pai dando ao filho as respostas dos exercícios de matemática após seu pedido de ajuda, e discutiu as possíveis conseqüências disso. Novamente, foi explicado que a cada comportamento de reforçar o desempenho correto do filho seria apresentada uma ficha azul escuro (como foi feito na Etapa A); quando fornecesse instruções para que o filho resolvesse o exercício seria apresentada uma ficha azul claro (como foi feito na Etapa B); toda vez que ela punisse o comportamento da criança quando ela errasse um exercício seria apresentada uma ficha bege escuro (como foi feito na Etapa C) e, nessa etapa, quando resolvesse um exercício pela criança seria apresentada uma ficha bege claro. Para cada ficha bege apresentada seria retirada uma ficha azul no final da sessão.

Fase 4 - Retorno à Linha de Base II: a Fase 4 foi realizada para checar a manutenção dos comportamentos emitidos pelas mães durante as sessões, após a intervenção. O mesmo procedimento da Fase 2 foi empregado nessa fase.

Fase 5 - Retorno à Linha de Base I: a Fase 5 também foi realizada para checar a manutenção dos comportamentos emitidos pelas mães durante as sessões após a intervenção sem a presença da pesquisadora. O mesmo procedimento da Fase 1 foi empregado nessa fase.

\section{Resultados e Discussão}

De acordo com os gráficos da Dupla 1, na Figura 1, pode-se observar que, com a introdução da intervenção, houve um aumento na taxa de respostas nas categorias "reforçar o comportamento da criança" e"dar instruções para criança" e uma diminuição na taxa de repostas nas categorias "punir o comportamento da criança" e "fazer o exercício pela criança".

A taxa do comportamento da mãe de "reforçar o comportamento da criança" (Figura 1A) aumentou, sendo que na Fase 1 (Linha de Base I) a taxa média era de 0,015 R/min passando para uma taxa média de 0,32 R/min na Fase 5 (Retorno à Linha de Base I). Essa mãe, na Fase 5, apresentou os comportamentos de abraçar, beijar, comemorar e elogiar o filho quando ele acertava um exercício. Aparentemente a qualidade da interação entre os dois melhorou depois de iniciada a 


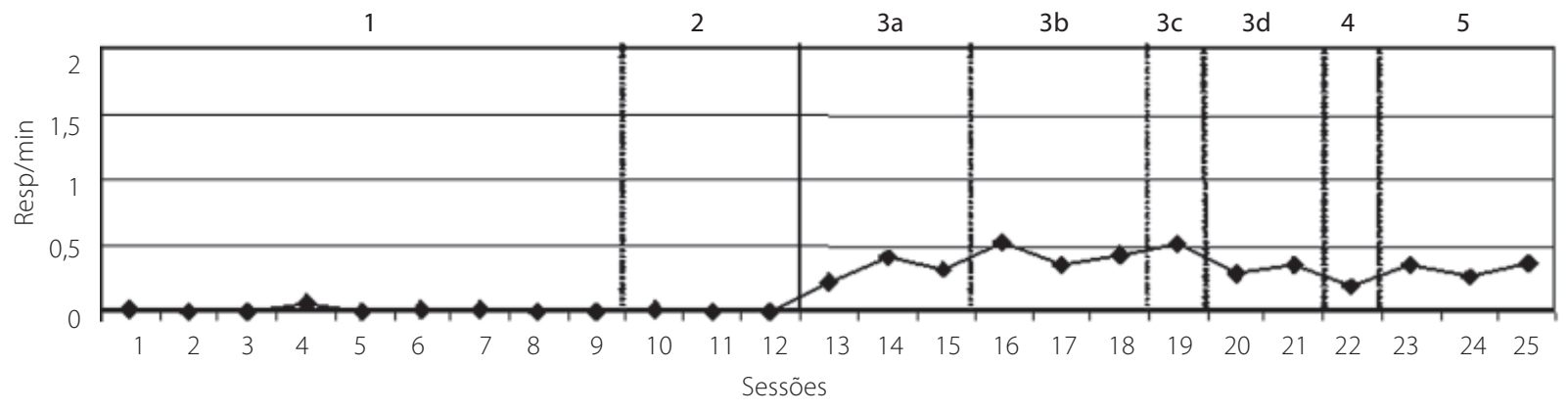

B

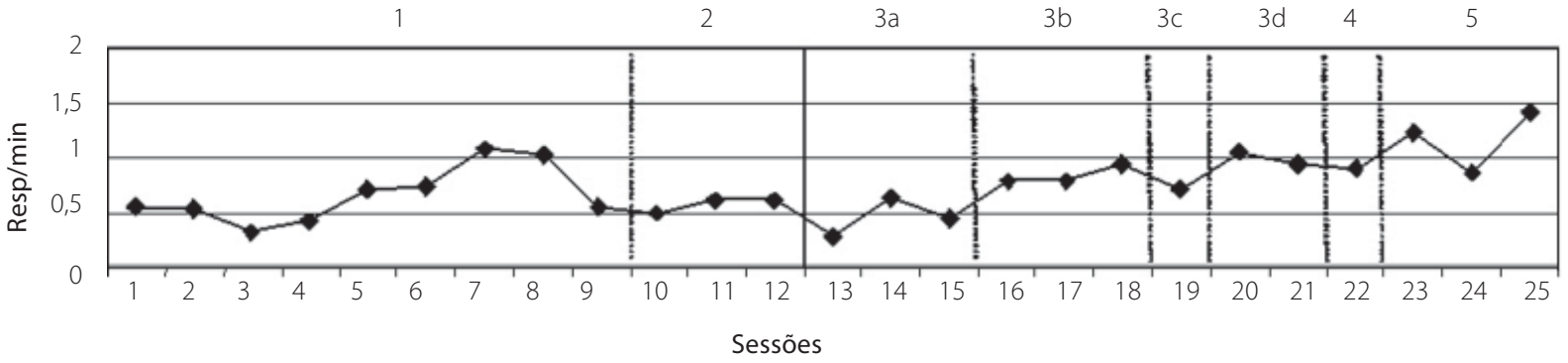

C

Punir o comportamento da criança

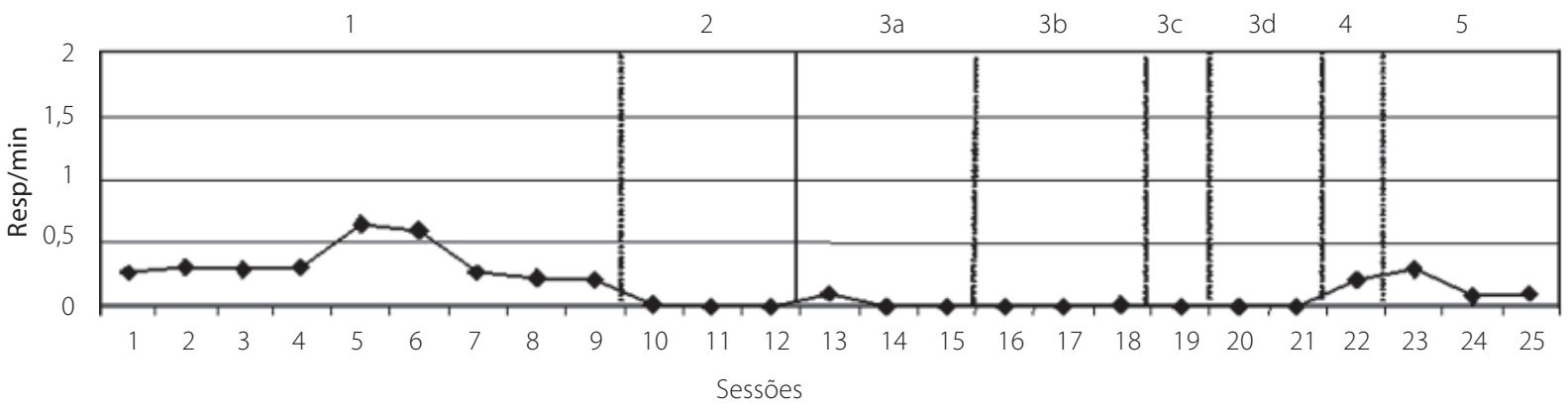

D

Fazer pela criança

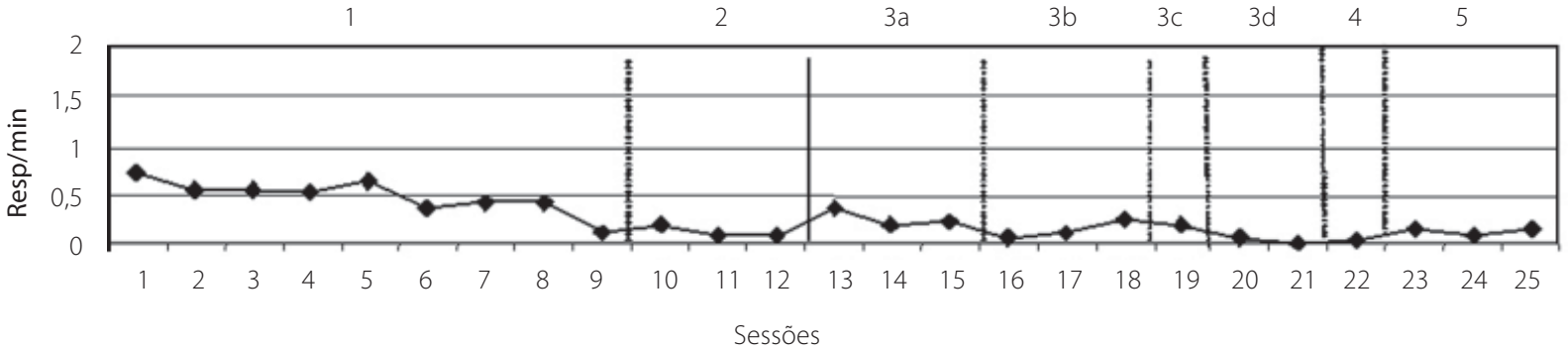

Figura 1. Respostas por minuto apresentadas pela mãe da Dupla 1 em cada uma das Fases.

Nota: $\mathbf{1}$ = Linha de Base l; $\mathbf{2}$ = Linha de Base II; $\mathbf{3} \mathbf{a}=$ Intervenção para categoria "reforçar o comportamento da criança"; $\mathbf{3} \mathbf{b}=$ Intervenção para categoria "dar instruções"; $\mathbf{3 c}=$ Intervenção para categoria "punir o comportamento da criança"; $3 \mathbf{d}=$ Intervenção para categoria "fazer o exercício pela criança"; $\mathbf{4}$ = Retorno à Linha de Base II; $\mathbf{5}$ = Retorno à Linha de Base I. 
intervenção, quando a mãe aumentou a taxa de respostas de "reforçar o comportamento da criança". Apesar de não terem sido registradas, observou-se que mãe e filho passaram a dar mais risadas durante a sessão depois de iniciada a intervenção.

A freqüência do comportamento "dar instruções para a criança" aumentou (Figura 1B). Esse comportamento apresentou uma média de 0,66 R/ min na Fase 1 (Linha de Base I) e aumentou para uma taxa média de 0,85 R/mim na Etapa B da Fase 3, na qual se iniciou a intervenção para esse comportamento. Na Fase 5 (Retorno à Linha de Base I) esse comportamento ocorreu com uma taxa média de $1,18 \mathrm{R} / \mathrm{min}$.

A categoria comportamental "punir o comportamento da criança" (Figura 1C) ocorreu com uma taxa média de 0,35 R/min durante a Fase 1 (Linha de Base I). Aparentemente, a mera presença da experimentadora na sala foi suficiente para reduzir as ocorrências desses comportamentos para uma taxa média de 0,006 R/min conforme sugerem os resultados da Fase 2. A taxa desse comportamento permaneceu baixa durante toda a intervenção $(0,13 \mathrm{R} / \mathrm{min}$ - média das taxas de respostas durante toda a 3, chegando a zero em algumas sessões) e voltou a ocorrer com maior freqüência nas sessões finais (i.e., Fase 4 e na primeira sessão da Fase 5) com uma taxa média de 0,25 R/min nessas duas sessões. Nas duas últimas sessões a ocorrência desses comportamentos voltou a cair.

À categoria "fazer o exercício pela criança" se apresentava com uma média de 0,46 R/min na Fase 1 (Linha de Base I). Com a presença da pesquisadora dentro da sala esse comportamento diminuiu para uma taxa média de 0,35 R/min (Figura 1D). Durante a Etapa D da Fase 3, em que foi introduzida a intervenção para esse comportamento, pode ser observada uma taxa média de 0,03 R/min. Após a intervenção, a taxa média desse comportamento foi de $0,03 \mathrm{R} / \mathrm{min}$ na Fase 4 (Retorno à Linha de Base II) e 0,12 R/min na Fase 5 (Retorno à Linha de Base I).

As mudanças nos comportamentos da mãe da Dupla 2 foram menores do que aquelas observadas para a Dupla 1. A categoria comportamental "reforçar o comportamento da criança" (Figura 2A) teve uma taxa média de respostas de 0,26 R/min na Fase 1 (Linha de Base I). Quando a pesquisadora estava na sala (Fase 2 -
Linha de Base II), a taxa média foi de 0,18 R/min, aumentando para uma taxa média de 0,53 R/min durante a Fase 3 (Intervenção). Após a intervenção, na Fase 4 (Retorno à Linha de Base II) e na Fase 5 (Retorno à Linha de Base I), as taxas médias foram de 0,12 R/min e 0,29 R/ min, respectivamente, o que indica que o efeito da intervenção não foi mantido após sua suspensão, havendo um retorno para os níveis de linha de base. A mãe da Dupla 2 já emitia o comportamento de reforçar o desempenho adequado do filho na Fase 1 (Linha de Base I). Apesar de os dados indicarem que a intervenção não foi efetiva para essa categoria com essa dupla, observações não sistemáticas das fitas de vídeo com as interações entre a mãe e a criança sugeriram que a mãe tenha ampliado a classe de respostas para elogiar o comportamento do seu filho. Após a intervenção, ela não apenas balançava a cabeça (como fazia na Fase 1), mas também sorria e dizia, por exemplo, "certo","parabéns" e "muito bem".

O comportamento de "dar instruções"(Fase 1 Linha de Base I) apresentava-se com uma taxa média de 1,19 R/min. Durante a Fase 3, Etapa B (quando se iniciou a intervenção para esse comportamento) houve um ligeiro aumento na taxa média para 1,45 R/ min (Figura 2B). Ao final da pesquisa (Fase 5 - Retorno à Linha de Base I) o comportamento de "dar instruções" estava sendo emitido com uma taxa média de 1,29 R/ min. Verifica-se, então, que apesar de ter havido um aumento na taxa de respostas para essa categoria esse aumento não se mostrou muito expressivo já que a mãe apresentava esse comportamento com alta freqüência antes da intervenção.

Conforme mostra a Figura 2C, a taxa de respostas da categoria comportamental "punir o comportamento da criança"se manteve baixa desde a Fase 1. A mãe da Dupla 2 apresentou uma taxa média de 0,06 R/min na Fase 1 (Linha de Base I), e durante as outras fases da pesquisa esse comportamento foi para uma taxa zero, ou seja, a mãe não puniu o comportamento da criança até o final da pesquisa.

Em relação à categoria comportamental "fazer o exercício pela criança" (Figura 2D), a taxa média foi de 0,36 $\mathrm{R} /$ min, diminuindo quando a pesquisadora entrou na sala (Fase 2) e durante as etapas de intervenção $(0,1 \mathrm{R} / \mathrm{min}$, 0,07 R/min, 0,16 R/min e 0,07 R/min - Etapa A, B, C e D, respectivamente). Quando houve o retorno à condição 


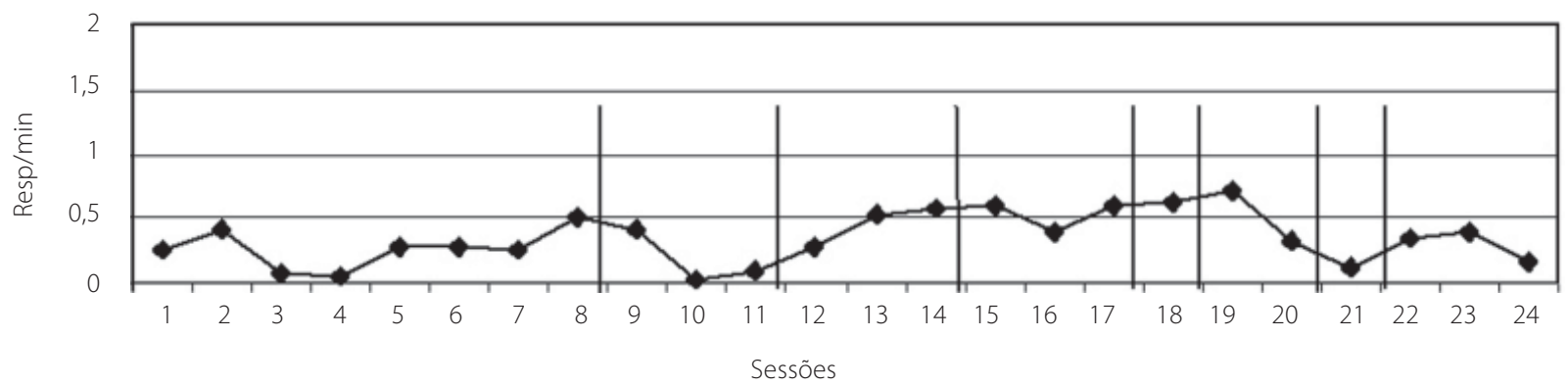

B

Dar instruções

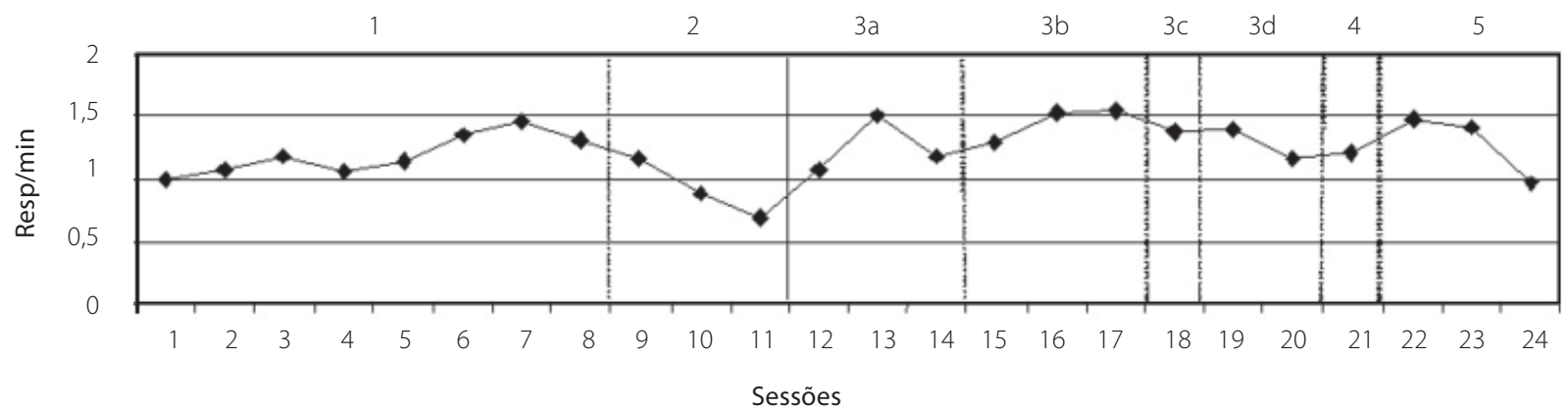

C

Punir o comportamento da criança

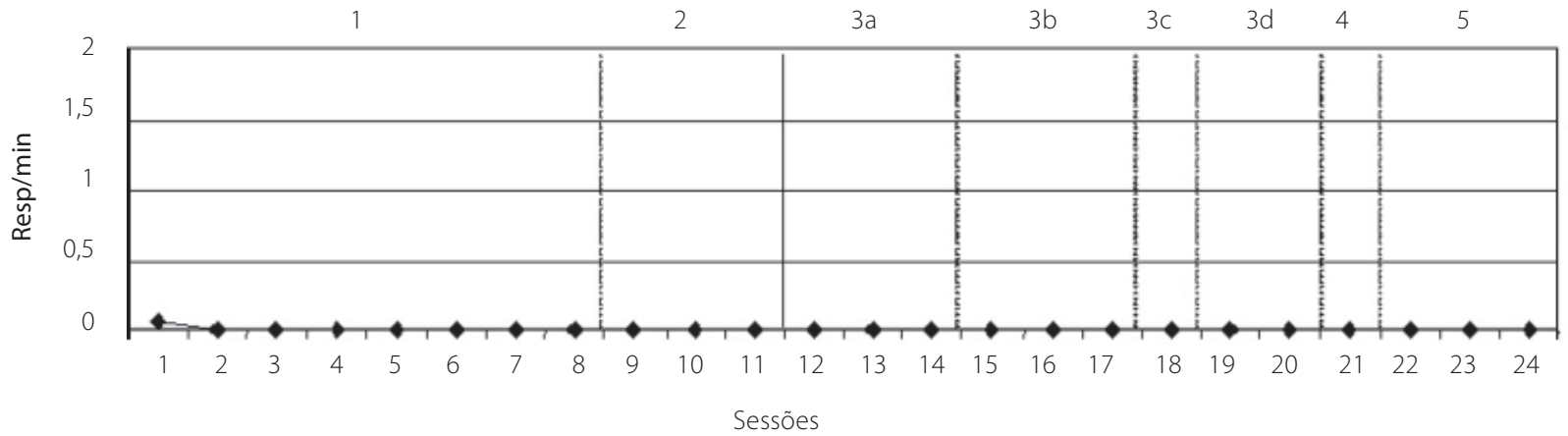

D

Fazer pela criança

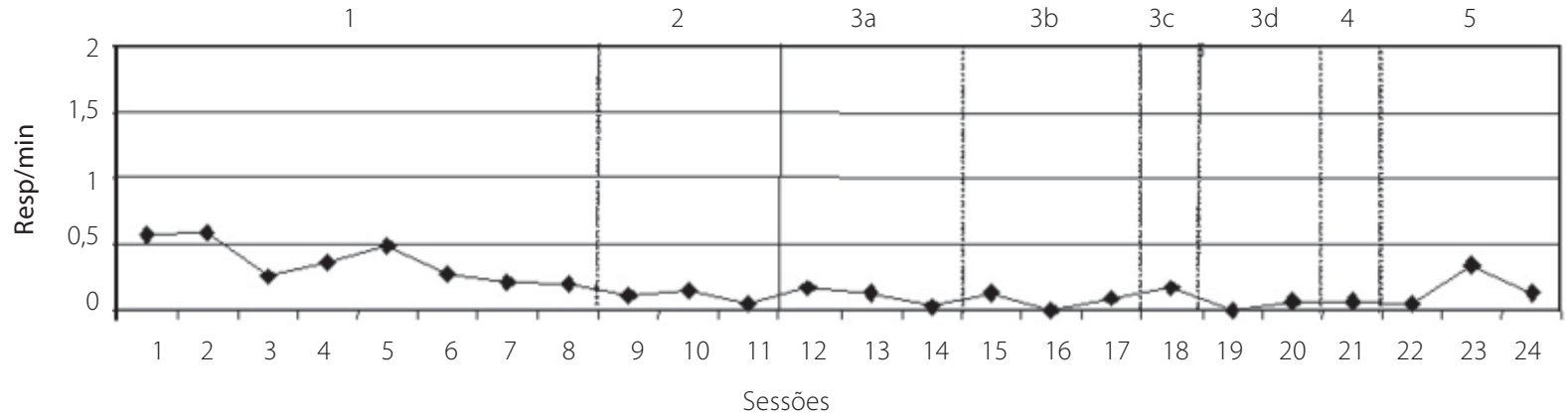

Figura 2. Respostas por minuto apresentadas pela mãe da Dupla 2 em cada uma das Fases.

Nota: $\mathbf{1}$ = Linha de Base l; $\mathbf{2}$ = Linha de Base II; $\mathbf{3 a}$ = Intervenção para categoria "reforçar o comportamento da criança"; $\mathbf{3} \mathbf{b}=$ Intervenção para categoria "dar instruções"; $\mathbf{3 c}=$ Intervenção para categoria "punir o comportamento da criança"; $\mathbf{3 d}=$ Intervenção para categoria"fazer o exercício pela criança"; 4 = Retorno à Linha de Base II; $\mathbf{5}$ = Retorno à Linha de Base I. 
de linha de base (Fases 4 e 5), a taxa permaneceu baixa (0,06 e 0,16 R/min, respectivamente), exceto pela segunda sessão da Fase 5.

\section{Considerações Finais}

Comparando-se os resultados obtidos com as duas duplas constata-se que diferenças mais expressivas nas taxas de respostas foram observadas para a Dupla 1.

Os dados indicam ainda que, com ambas as duplas, houve uma diminuição na taxa de respostas com a entrada da experimentadora na sala. Especulase que isso possa ter ocorrido pela simples presença de uma pessoa estranha no momento da interação entre mãe e filho. Todavia, de maneira geral, com o início da intervenção houve um aumento na freqüência de comportamentos "adequados" e uma diminuição dos "inadequados".

Apesar de as mudanças comportamentais terem ocorrido durante a fase de intervenção verificou-se que quando houve a interrupção dessa fase (i.e., durante a Fase 5) os comportamentos tenderam, em algumas categorias (e.g., "punir o comportamento da criança", no caso da Dupla 1; "reforçaro comportamento da criança" e "dar instruções" no caso da Dupla 2 e "fazer pela criançd" em ambas as duplas) a se aproximar dos níveis da linha de base.

No trabalho realizado por Sampaio et al. (2004) os resultados sugeriram que o treinamento dado às mães se mostrou efetivo para aumentar a taxa de respostas da mãe "conferir a tarefa" e "elogiar" e diminuir a taxa de respostas da mãe "fazer o exercício pela criança", entretanto a taxa de respostas do comportamento de dar instruções não sofreu alteração. De maneira geral, os resultados do presente trabalho mostraram uma maior alteração nas taxas dos comportamentos das mães se comparados aos obtidos por Sampaio et al.

Também no presente trabalho houve, como no de Sampaio et al. (2004), uma melhora na qualidade das instruções. Após a intervenção as mães passaram a verbalizar instruções mais elaboradas para que as crianças chegassem à resposta correta. Por exemplo, no início do estudo as instruções eram dadas da seguinte maneira "coloque o dois aqui", "escreva aqui" ou "3 × 5 é...". Após a intervenção foram observadas instruções como "leia novamente", "apague o que escreveu", "o que está escrito aqui?", "como será que se faz este problema?", "coloque isto que você disse aqui", "verifique se está certo".

Alguns problemas apareceram durante a realização da presente pesquisa, tais como: (a) a impossibilidade de aumentar o número de sessões de linha de base, de intervenção e de retorno à linha de base pelo pouco tempo disponível para a realização do trabalho devido à proximidade das férias escolares - entre os meses de dezembro e março as atividades na escola foram interrompidas -, e (b) a impossibilidade da realização de follow-up pelo mesmo motivo.

A partir daí algumas modificações podem ser sugeridas para estudos posteriores, dentre elas:

- aumentar o número de sessões de linha de base, de intervenção e de retorno à linha de base, e conseqüentemente o tempo de registro dos comportamentos a fim de visualizar com maior precisão a estabilidade das taxas de respostas;

- utilizar um programa de reforço intermitente, durante a intervenção, para fortalecer os comportamentos adequados e assim aumentar a resistência à extinção desses comportamentos após a retirada da intervenção;

- utilizar um procedimento de fading out-retirada gradual da intervenção para favorecer a manutenção das mudanças;

- realizar sessões de follow-up após o término da pesquisa para demonstrar se as mudanças ocorridas se mantiveram;

- fazer uso de modelação - fornecer à mãe modelos de interação adequados durante a realização da tarefa.

Outro ponto importante a ser discutido diz respeito à generalização dos comportamentos-alvo desta pesquisa. Observações estendidas para o ambiente doméstico poderiam indicar se os comportamentos treinados durante as sessões na escola se generalizam para aquele contexto.

Maiores investigações são necessárias devido à relevância do tema e para o aprimoramento da metodologia de intervenção. 


\section{Referências}

Eilam, B. (2001). Primary strategies for promoting homework performance. American Educational Research Journal, 38 (3), 691-725.

Fehrmann, P. G., Keith, T. Z., \& Reimers, T. M. (1987). Home influence on school learning: direct and indirect effects of parental involvement on high school grades. Journal of Educational Research, 80 (6), 330-337.

Grolnick, W. S., \& Slowiaczek, M. L. (1994). Parent's involvement in children's schooling: a multidimensional conceptualization and motivational model. Child Development, 65 (1), 237-252.

Guhl, B., \& Fontenelle, D. H. (1997). Pais perfeitos (pp.12-75). Blumenau: EKO.

Hübner, M. M. (1999). Contingências e regras familiares que minimizam problemas de estudo: a família pró-saber. In R. R. Kerbauy \& R. C. Wielenska (Orgs.). Sobre comportamento e cognição: psicologia comportamentale cognitiva da reflexão teórica à diversidade da aplicação (v.4, pp.251-256). Santo André: ARBytes.

Hübner, M. M., \& Marinotti, M. (2000). Crianças com dificuldades escolares. In E. F. M. Silvares (Org.). Estudos de caso em Psicologia Clínica Comportamental Infantil (v.2, pp.259-304). Campinas: Papirus.

Jenson, W. R., Sheridan, S. M., Olympia, D., \& Andrews, D. (1994). Homework and students with learning disabilities and behavior disorders: a practical, parent-based approach. Journal of Learning Disabilities, 27 (9), 538-548.

Marturano, E. M. (1999) Recursos no ambiente familiar e dificuldades de aprendizagem na escola. Psicologia: Teoria e Pesquisa, 15, 135-142.

Matos, M. A. (1993) Análise de contingências no aprender e no ensinar. In E.S. Alencar (Org). Novas contribuições da Psicologia aos processos de ensino e aprendizagem (2.ed. pp.141-165). São Paulo: Cortez.

Sampaio, A. C. P., Souza, S. R., \& Costa, C. E. (2004). Teinamento de mães no auxílio à execução da tarefa de casa. In M. Z. S. Brandão, F. C. S. Comte, F. S. Brandão, Y. K. Ingbergman, V. L. M. Silva \& S. M. Oliani (Orgs.). Sobre comportamento e cognição: contribuições para a construção da teoria do comportamento (v.14, pp.295-309). Santo André: ESETec.

Soares, M. R. Z., Souza, S. R., \& Marinho, M. L. (2004). Envolvimento dos pais: incentivo à habilidade de estudo em crianças. Estudos de Psicologia, 21 (3), 253-260.

Tomanari, G. Y. (2000). Reforçamento condicionado. Revista Brasileira de Terapia Comportamental e Cognitiva, 2 (1), 67-77.

Zagury, T. (2002). Escola sem conflito: parceria com os pais. Rio de Janeiro: Record.

Recebido em:18/3/2005

Versão final reapresentada em: 15/09/2005

Aprovado em: 14/10/2005 